Virginia Commonwealth University VCU Scholars Compass

2013

\title{
The effect of sulfur covalent bonding on the electronic shells of silver clusters
}

\author{
Anthony F. Pedicini \\ Virginia Commonwealth University, pediciniaf@vcu.edu \\ Arthur C. Reber \\ Virginia Commonwealth University, acreber@vcu.edu \\ Shiv N. Khanna \\ Virginia Commonwealth University, snkhanna@vcu.edu
}

Follow this and additional works at: http://scholarscompass.vcu.edu/phys_pubs

Part of the Physics Commons

Pedicini, A. F., Reber, A. C., \& Khanna, S. N. The effect of sulfur covalent bonding on the electronic shells of silver clusters. The Journal of Chemical Physics, 139, 164317 (2013). Copyright (C) 2013 AIP Publishing LLC.

\section{Downloaded from}

http://scholarscompass.vcu.edu/phys_pubs/108

This Article is brought to you for free and open access by the Dept. of Physics at VCU Scholars Compass. It has been accepted for inclusion in Physics Publications by an authorized administrator of VCU Scholars Compass. For more information, please contact libcompass@vcu.edu. 


\title{
The effect of sulfur covalent bonding on the electronic shells of silver clusters
}

\author{
Anthony F. Pedicini, Arthur C. Reber, and Shiv N. Khanna ${ }^{a)}$ \\ Department of Physics, Virginia Commonwealth University, Richmond, Virginia 23284, USA
}

(Received 25 August 2013; accepted 13 October 2013; published online 30 October 2013)

\begin{abstract}
The nature of the bonding in $\operatorname{Ag}_{n} \mathrm{~S}_{m}{ }^{0 /-}$ clusters, $n=1-7 ; m=1-4$, has been analyzed to understand its effect on the electronic shell structure of silver clusters. First-principle investigations reveal that the sulfur atoms prefer 2 or 3-coordinate sites around a silver core, and that the addition of sulfur makes the planar structures compact. Molecular orbital analysis finds that the $3 p$ orbitals of sulfur form a bonding orbital and two weakly bonding lone pairs with silver. We examine the electronic shell structures of $\mathrm{Ag}_{6} \mathrm{~S}_{\mathrm{m}}$, which are two electrons deficient of a spherical closed electronic shell prior to the addition of sulfur, and $\mathrm{Ag}_{7} \mathrm{~S}_{\mathrm{m}}{ }^{-}$clusters that contain closed electronic shells prior to the addition of sulfur. The $\mathrm{Ag}_{6} \mathrm{~S}_{4}$ cluster has a distorted octahedral silver core and an open shell with a multiplicity of 3 , while the $\mathrm{Ag}_{7} \mathrm{~S}_{\mathrm{n}}{ }^{-}$clusters have compact geometries with enhanced stability, confirming that the clusters maintain their electronic shell structure after bonding with sulfur. (C) 2013 AIP Publishing LLC. [http://dx.doi.org/10.1063/1.4827091]
\end{abstract}

\section{INTRODUCTION}

Noble metal particles have always attracted attention, largely due to their optical properties and it was almost 150 years ago that Faraday synthesized and demonstrated the colors of colloidal gold. ${ }^{1}$ The properties of this new state of matter have been found to be very different from the bulk and the synthesis of materials using selected clusters as the building blocks is a promising strategy for the design of new materials with desired characteristics. ${ }^{2}$ Metallic clusters, however, generally coalesce when assembled as bare entities and one needs ways to protect the individual clusters. One of the successful approaches to stabilize the new materials is to attach ligands that can prevent fusion of clusters as they are assembled. ${ }^{3-8}$ This approach has been particularly successful for noble metal clusters, and numerous atom-precise clusters based ligated gold and silver particle assemblies have been synthesized. ${ }^{9-20}$ Many of the ligands of choice use the sulfur containing thiol group and the passivation and stabilization of bare metallic clusters through the addition of thiols during synthesis also allows for the tuning of optical, physical, and electronic properties. ${ }^{21-37}$ In addition to pure species, as we showed in a recent work, the ligation allows stabilization of cluster based material containing even a bimetallic core. The new material consisted of $\mathrm{Ag}_{4} \mathrm{Ni}_{2}$ clusters ligated with DMSA where the silver and the nickel atoms are linked by $\mathrm{S}$ atoms. ${ }^{38}$

The conceptual framework over which the cluster's stability may be understood is the superatom model which finds that clusters with a zero effective valence may be found when the number of itinerant valence electrons in the metallic core corresponds to an electronic shell closing. ${ }^{39}$ This model has been quite successful in rationalizing the stability of bare and ligand protected clusters. ${ }^{8,25,39}$ The silver (or

\footnotetext{
a) Author to whom correspondence should be addressed. Electronic mail: snkhanna@vcu.edu
}

gold) atoms provide one delocalized valence electron as the atomic configuration $4 d^{10} 5 s^{1}\left(5 d^{10} 6 s^{1}\right)$ where the $d$ electrons are filled and the $5 s$ are delocalized as a diffuse electron gas. The confined nearly free electron gas results in electronic states that are grouped into shells with effective quantum numbers in a spherical cluster of $1 \mathrm{~S}^{2}, 1 \mathrm{P}^{6}, 1 \mathrm{D}^{10}, 2 \mathrm{~S}^{2}$ with corresponding magic numbers of $2,8,18$, and $20 .^{40,41}$ These closed electronic shell structures have large HOMOLUMO gaps, reduced reactivity with molecular oxygen, and enhanced stability. ${ }^{42,43}$ For nonspherical metallic clusters, the electron gas undergoes a crystal field like splitting, ${ }^{43-46}$ for example, $\mathrm{Ag}_{6}$ has six valence electrons and a planar structure, so the $1 \mathrm{P}^{6}$ orbitals are split into two low lying $1 \mathrm{P}_{\mathrm{x}}$ and $1 \mathrm{P}_{\mathrm{y}}$ orbitals, and an unoccupied $1 \mathrm{P}_{\mathrm{z}}$ orbital resulting in a large HOMO-LUMO gap. The addition of sulfur ligands reduces the effective valence electron count by moving a delocalized electron into a localized bonding orbital. To understand the fundamental principles underlying this model, we seek to understand the bonding between sulfur and noble metals and the effect of the bonding on the electronic shell structure of the noble metal cluster. To do this, we investigate the stability and reactivity of $\operatorname{Ag}_{n} S_{m}$ clusters as the simplest model system which may help develop such a base of knowledge.

The purpose of this paper is to present first principles theoretical studies on the atomic structure, electronic structure, and reactivity of neutral and anionic $\mathrm{Ag}_{n} \mathrm{~S}_{m}{ }^{0 /-}$ clusters, $n=1-7 ; m=1-4$. In addition to the silver cluster based materials, our work is motivated by recent studies on the effect of sulfur on the stability of Ag nanoislands. ${ }^{47}$ The studies indicate that the presence of sulfur enhances the coarsening of $\mathrm{Ag}$ nanoislands on $\mathrm{Ag}(100)$. An analysis of the experimental data suggests that $\mathrm{AgS}_{2}$ cluster might be active for such a coarsening. Our studies on the stability of the cluster towards the removal of a $\mathrm{Ag}$ or $\mathrm{S}$ atom may be useful to develop a physical picture. We would like to add that the atomic and electronic structure of neutral and charged silver clusters $\mathrm{Ag}_{n}, \mathrm{Ag}_{n}{ }^{-}$, 
and $\mathrm{Ag}_{n}{ }^{+}$have attracted attention in several studies. ${ }^{43,48-52} \mathrm{~A}$ recent study has also focused on the structure of $\mathrm{Ag}_{n} \mathrm{~S}_{4}{ }^{-}$ $(n=1-7)$ clusters that have been generated by the electrospray ionization of $\mathrm{Ag}_{7}(\mathrm{DMSA})_{4}{ }^{-}$, offering a mechanism for the production of $\mathrm{Ag}_{\mathrm{n}} \mathrm{S}_{\mathrm{n}}{ }^{-}$clusters. ${ }^{51,53}$ There are several other studies on small $\mathrm{AgS}_{\mathrm{m}},{ }^{54} \mathrm{Ag}_{2 \mathrm{n}} \mathrm{S}_{\mathrm{n}},{ }^{55}$ and $\mathrm{Au}_{\mathrm{n}} \mathrm{S}^{+}$ clusters. ${ }^{56}$ However, a comprehensive investigation of the nature of the electronic structure modification of silver clusters through the addition of sulfur has yet to be explored. The present work is designed to fill this gap as it focuses on the electronic stability and properties of small silver-sulfur clusters through the sequential increases of $\mathrm{Ag}$ and incremental addition of $\mathrm{S}$ within $\mathrm{Ag}_{n} \mathrm{~S}_{m}$ and $\mathrm{Ag}_{n} \mathrm{~S}_{m}{ }^{-}$. In particular, we examine the electronic shell structures of $\mathrm{Ag}_{6} \mathrm{~S}_{\mathrm{m}}$, which are two electrons deficient of a spherical closed electronic shell prior to the addition of sulfur, and the $\mathrm{Ag}_{7} \mathrm{~S}_{\mathrm{m}}{ }^{-}$clusters that also contain closed electronic shells prior to addition of sulfur. This comparison reveals that the electronic shell structure of the silver clusters is still apparent after the addition of sulfur, and highlights the effect of bonding at the silver-sulfur interface.

\section{THEORETICAL METHODS}

First-principles electronic structure calculations on the neutral and anionic $\operatorname{Ag}_{n} \mathrm{~S}_{m}$ clusters were carried out within a gradient-corrected density-functional approach ${ }^{57}$ The electronic orbitals are represented by a linear combination of atomic orbitals that are formed, in turn, through a linear combination Slater-type orbitals (STO) located at the atomic sites. Actual calculations were completed using the Amsterdam Density Functional (ADF) set of codes. ${ }^{58}$ To determine the ground state many initial geometries and spin multiplicities were sampled. All structures were fully optimized without constraint or symmetry to allow for full variational freedom. The clusters' molecular orbitals were assigned subshell distinctions through inspection of their nodes in the calculated wave function. The exchange and correlation effects were approximated using the gradient corrected functional proposed by Perdew, Burke, and Ernzerhof (PBE) ${ }^{57}$ Relativistic effects were included using the Zeroth Order Regular Approximation ${ }^{56}$ while employing a TZ2P basis and Large frozen electron core for both silver and sulfur atoms.

A fragmentation analysis as implemented within ADF was performed to get a deeper insight into the nature of the bonding. ${ }^{58-60}$ In this analysis the system in question is considered as a sum of "fragments," each fragment yielding a basis set. The fragments are then combined to calculate the electronic structure of the full system. Here, we chose the silver cluster and the sulfur atoms themselves to serve as fragments. This procedure allows for both the analysis of the change in charge density within the cluster using the charge density of its composite fragments and also yields the requisite information needed in determining which orbitals are involved in bonding. Our calculated bond lengths for $\mathrm{Ag}-\mathrm{Ag}, \mathrm{Ag}-\mathrm{S}$, and S-S bonds are 2.60, 3.40, and $1.92 \AA$ compared to the experimental values of $2.53 \AA$ for the Silver dimer ${ }^{61}$ and $1.89 \AA$ for the Sulfur dimer, and no experimental result is available for $\mathrm{AgS}$. The calculated bond strengths of $1.68 \mathrm{eV},{ }^{62} 2.40 \mathrm{eV}$,

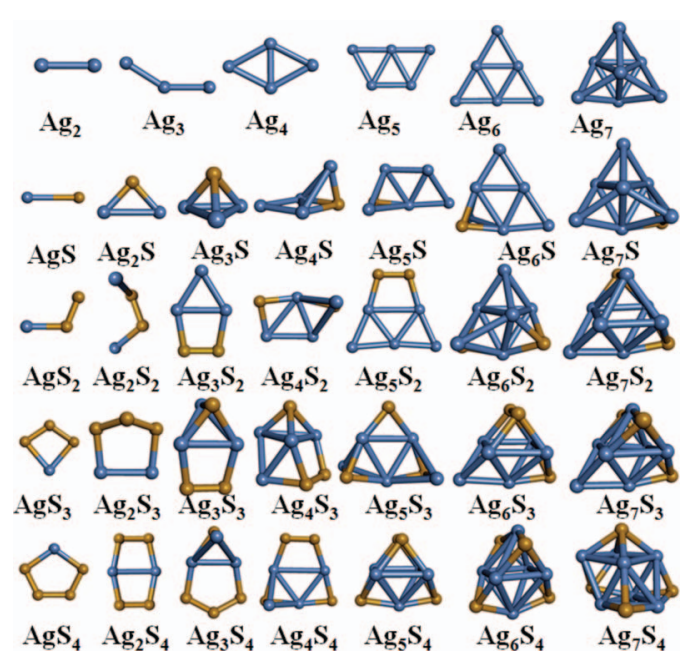

FIG. 1. Ground state geometries of neutral $\mathrm{Ag}_{n} \mathrm{~S}_{m}$ clusters, with $n=1-7$ and $m=0-4$.

and $5.23 \mathrm{eV}$ are also comparable to experimental values of $1.66 \mathrm{eV}$ for $\mathrm{Ag}-\mathrm{Ag}$, and $4.40 \mathrm{eV}$ for $\mathrm{S}-\mathrm{S}$ bonds.

\section{RESULTS AND DISCUSSION}

The ground state geometries of the neutral $\mathrm{Ag}_{\mathrm{n}} \mathrm{S}_{\mathrm{m}}$ clusters are shown in Figure 1, and the anionic structures are shown in Figure 2. In all of the clusters with more than 3 silver atoms, the ground state structure is found to have a metallic center with all of the $\mathrm{Ag}$ atoms coordinated to one another, with sulfur binding at the periphery of the silver core. We are first interested in two features of the clusters: (1) how does the addition of sulfur affect the geometry of the silver core and (2) which sites of the silver cluster do the sulfur atoms prefer to bond? The $\mathrm{Ag}_{\mathrm{n}}$ clusters are planar for $\mathrm{n} \leq 6$ atoms as is expected based on the electron count. For neutral $\operatorname{Ag}_{n} S_{m}$ clusters, the addition of sulfur leads to non-planar structure at smaller numbers of silver atoms than the $\mathrm{Ag}_{\mathrm{n}}$ clusters. For example, the metallic cores in $\mathrm{Ag}_{4} \mathrm{~S}, \mathrm{Ag}_{5} \mathrm{~S}$, and $\mathrm{Ag}_{6} \mathrm{~S}$ are all nonplanar, with the sulfur displacing one silver atom from a

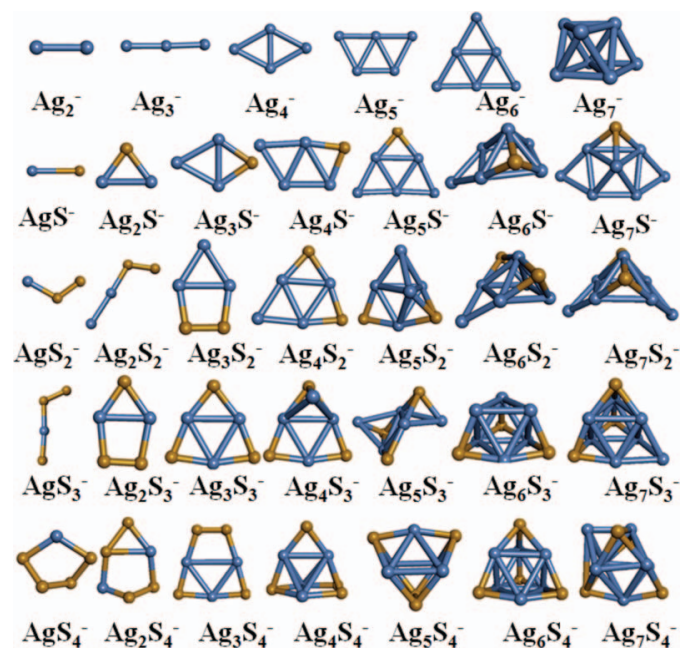

FIG. 2. Ground state geometries of $\mathrm{Ag}_{n} \mathrm{~S}_{m}{ }^{-}$clusters, with $n=1-7$ and $m=0-4$. 
planar geometry. The addition of successive sulfur eventually produces a compact metal core as seen in $\mathrm{Ag}_{4} \mathrm{~S}_{3}, \mathrm{Ag}_{5} \mathrm{~S}_{4}$, and $\mathrm{Ag}_{6} \mathrm{~S}_{3}$. The $\mathrm{Ag}_{7}$ cluster is essentially in a compact geometry for the pure cluster, so the addition of sulfur does not significantly compact the metallic core. The binding site of the sulfur for clusters with one or two silver atoms results in ring structures and sulfur-sulfur bonding; however, for clusters with more than three silver atoms, the predominant binding sites are the ones in which the sulfur atom binds to a 3coordinated site with three silver atoms forming a distorted tetrahedron. There are a few cases of the sulfur forming a disulfide bond, in which adjacent sulfurs bind together, as seen in $\mathrm{Ag}_{5} \mathrm{~S}_{2}, \mathrm{Ag}_{5} \mathrm{~S}_{4}$, and $\mathrm{Ag}_{6} \mathrm{~S}_{3}$. Of particular interest is the $\mathrm{Ag}_{6} \mathrm{~S}_{4}$ cluster which has a structure in which the silver core forms a distorted octahedron, and the four sulfur atoms bind to 3-coordinated sites. The ground state structure of $\mathrm{Ag}_{6} \mathrm{~S}_{4}$ is found to have a multiplicity of 3 corresponding to spin magnetic moment of $2 \mu_{\mathrm{b}}$.

Figure 2 shows the ground state atomic structures of the anionic $\mathrm{Ag}_{n} \mathrm{~S}_{m}{ }^{-}$clusters. The progression from planar to nonplanar silver core occurs with more sulfur atoms than the neutral clusters, however, the transition still occurs in all cases. The smallest non-planar clusters for $n=4,5$, and 6 are $\mathrm{Ag}_{4} \mathrm{~S}_{3}{ }^{-}, \mathrm{Ag}_{5} \mathrm{~S}_{2}{ }^{-}$, and $\mathrm{Ag}_{6} \mathrm{~S}^{-}$. The metallic cores become compact with the additional sulfur, as seen in $\mathrm{Ag}_{4} \mathrm{~S}_{4}{ }^{-}$, $\mathrm{Ag}_{5} \mathrm{~S}_{4}{ }^{-}, \mathrm{Ag}_{6} \mathrm{~S}_{3}{ }^{-}$, and $\mathrm{Ag}_{7} \mathrm{~S}_{3}{ }^{-}$. There are several cases of the sulfur binding to the 2-coordinated sites on the edge of the metallic core; however, the most common binding site for the sulfur is the 3-coordinated site on top of three silver atoms. A disulfide bond is seen in $\mathrm{Ag}_{4} \mathrm{~S}_{4}{ }^{-}$and $\mathrm{Ag}_{5} \mathrm{~S}_{4}{ }^{-}$. Of particular interest is the $\mathrm{Ag}_{7} \mathrm{~S}_{4}{ }^{-}$cluster, as $\mathrm{Ag}_{7}{ }^{-}$has a closed electronic shell prior to the addition of sulfur, so the effect of the bonding of sulfur to a closed-shell cluster is especially intriguing.

To analyze the relative stability of the clusters, we next consider the removal energies (RE), the energy required to remove a single $\mathrm{Ag}$ or $\mathrm{S}$ atom from the cluster. These are calculated using the equation

$$
R E=E(A)+E\left(A_{x-1} B_{y}\right)-E\left(A_{x} B_{y}\right) .
$$

Here, $E(A), E\left(A_{x-1} B_{y}\right)$, and $E\left(A_{x} B_{y}\right)$ are the total energies of the $A$ atom, $A_{x-1} B_{y}$ cluster, and $A_{x} B_{y}$ cluster, respectively. Figures 3(a) and 3(b) show the removal energy trends of $\mathrm{Ag}$ and $\mathrm{S}$ from the $\mathrm{Ag}_{n} \mathrm{~S}_{m}$ clusters. The silver removal energies of Figure 3(a) demonstrate an even-odd pattern for the $\mathrm{Ag}_{\mathrm{n}}$ clusters, with $\mathrm{Ag}_{6}$ showing the largest removal energy. The $\mathrm{Ag}_{6} \mathrm{~S}_{m}$ clusters exhibit enhanced Ag removal energies from $m=0-3$ with the $\mathrm{Ag}_{\mathrm{n}} \mathrm{S}_{4}$ series having its largest peak at $\mathrm{Ag}_{5} \mathrm{~S}_{4}$. Note that $\mathrm{Ag}_{6} \mathrm{~S}_{4}$ has a triplet ground state that probably causes this break in the trend. At smaller sizes, no clear trend emerges after the addition of two or more sulfur atoms. Figure 3(b) plots the S removal energy of the neutral clusters, which are consistently much larger than the silver removal energies due to the strong covalent bond between sulfur and silver. The binding of the sulfur atoms is seen to increase with additional silver atoms, with $\mathrm{As}_{7} \mathrm{~S}$ having the largest $\mathrm{S}$ removal energy and with $\mathrm{AgS}$ having the smallest. The binding of the second sulfur atom is generally larger than for the first sulfur atom except for $\mathrm{Ag}_{2}$ and $\mathrm{Ag}_{4}$, with the largest sulfur removal energy being at $m=2$ for the $\mathrm{AgS}_{\mathrm{m}}$ and $\mathrm{Ag}_{7} \mathrm{~S}_{\mathrm{m}}$ clusters, 3 for

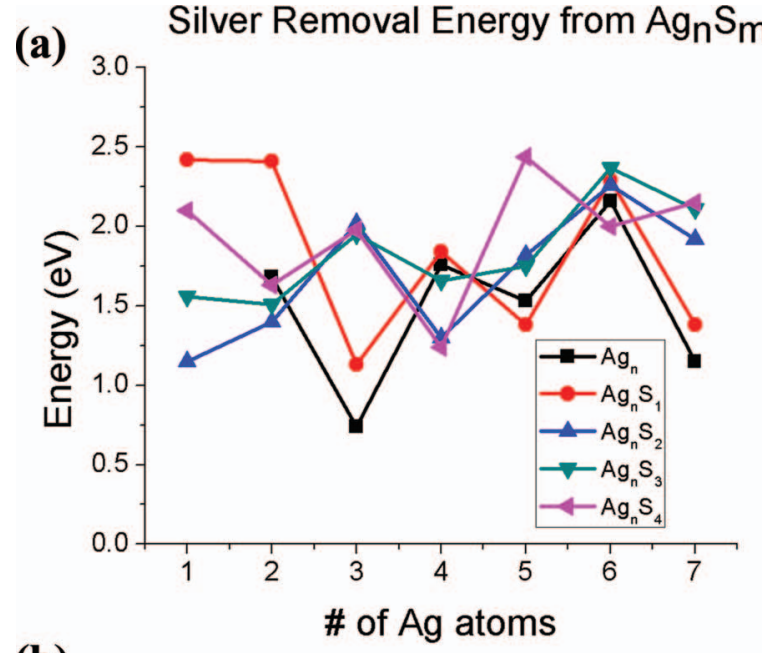

(b) Sulfur Removal Energy from $\mathrm{Ag}_{n} \mathrm{~S}_{\mathrm{m}}$

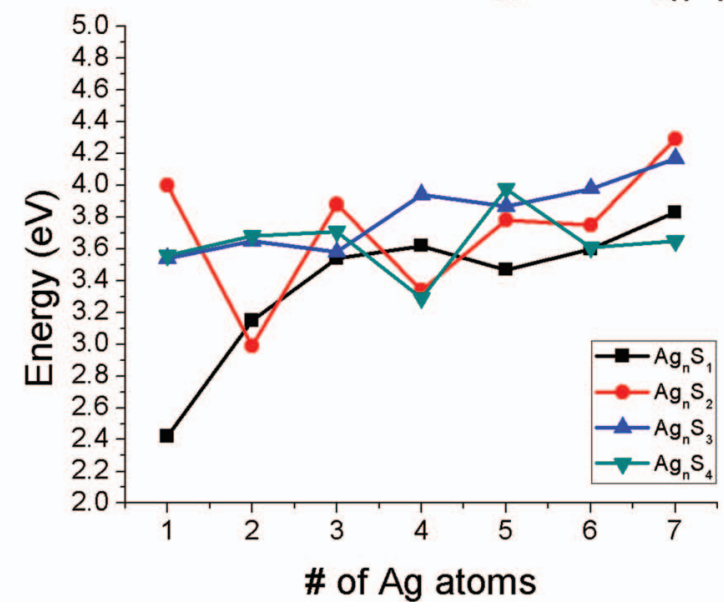

FIG. 3. Calculated removal energy plots for $\mathrm{Ag}$ (a) and $\mathrm{S}$ (b) in $\mathrm{Ag}_{n} \mathrm{~S}_{m}$.

$\mathrm{Ag}_{4} \mathrm{~S}_{\mathrm{m}}$ and $\mathrm{Ag}_{6} \mathrm{~S}_{\mathrm{m}}$, and 4 for $\mathrm{Ag}_{2} \mathrm{~S}_{\mathrm{m}}$ and $\mathrm{Ag}_{5} \mathrm{~S}_{\mathrm{m}}$. The clusters of $\mathrm{Ag}_{6} \mathrm{~S}_{m}$, which we have marked for particular interest shows that the $S$ removal energy initially increases with the addition of $S$, and the $S$ removal energy drops to its initial value with the addition of the fourth sulfur atom. This implies that the $\mathrm{Ag}_{6} \mathrm{~S}_{m}$ cluster series is becoming increasingly more stable through sulfur addition. As mentioned above, it has been suggested that a $\mathrm{AgS}_{2}$ complex might be playing a role in the coarsening of $\mathrm{Ag}_{\mathrm{n}}$ islands. The present study shows that this cluster has a low binding energy to remove a $\mathrm{Ag}$ atom while having a high energy to remove a $\mathrm{S}$ atom. The weak bonding of $\mathrm{Ag}$ seems consistent with the ability of $\mathrm{S}_{2}$ to transport $\mathrm{Ag}$ atoms. However, further work, and inclusion of kinetics, is needed to examine this island formation.

We next analyze the removal energies for the anionic clusters $\mathrm{Ag}_{n} \mathrm{~S}_{m}{ }^{-}$in Figures 4(a) and 4(b). An even-odd alternation in $\mathrm{Ag}$ removal energy for the $\mathrm{Ag}_{\mathrm{n}}{ }^{-}$and $\mathrm{Ag}_{\mathrm{n}} \mathrm{S}^{-}$series is seen in Figure 4(a), however for clusters with 2-4 sulfur atoms, the even-odd pattern is no longer apparent. This suggests that the bonding energy of the sulfur atom becomes more important to the stability of the cluster than the stabilization afforded by the shell closing of the metal cluster. The maximum silver removal energy for $m=2,3$, and 4 are found at $n=7,6$, and 5 respectively. The sulfur removal energies 


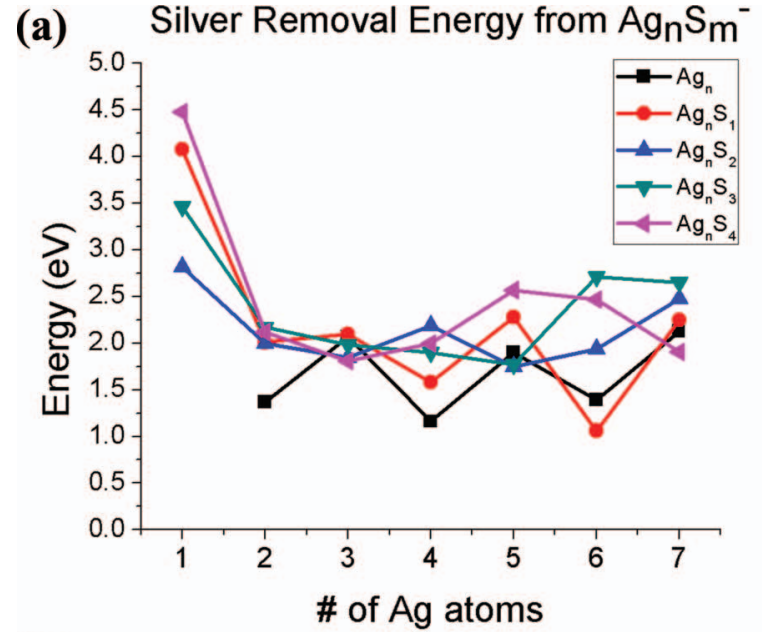

(b) Sulfur Removal Energy from $\mathrm{Ag}_{\mathrm{n}} \mathrm{S}_{\mathrm{m}}^{-}$

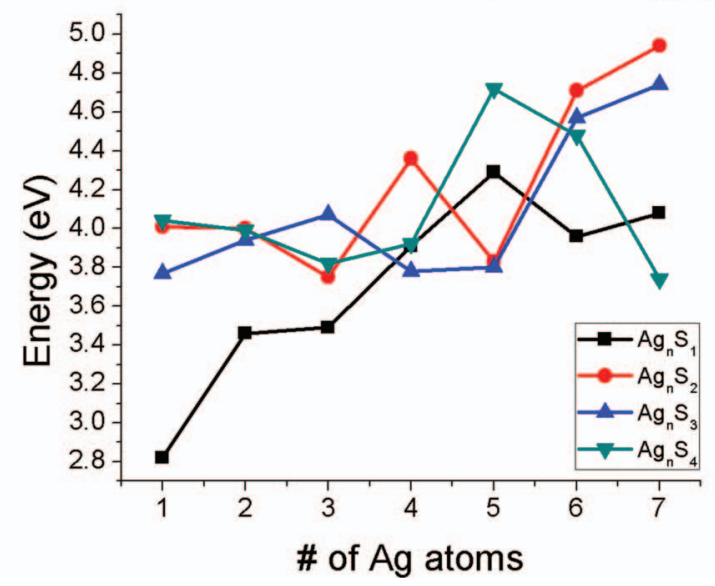

FIG. 4. Calculated removal energy plots for $\mathrm{Ag}(\mathrm{a})$ and $\mathrm{S}$ (b) in $\mathrm{Ag}_{n} \mathrm{~S}_{m}{ }^{-}$.

are shown in Figure 4(b), and it is seen that the addition of the second and third sulfur generally binds more strongly than the first sulfur, with the largest sulfur removal energy being $m=2$ for the $\mathrm{Ag}_{2} \mathrm{~S}_{\mathrm{m}}{ }^{-}, \mathrm{Ag}_{4} \mathrm{~S}_{\mathrm{m}}{ }^{-}, \mathrm{Ag}_{6} \mathrm{~S}_{\mathrm{m}}{ }^{-}$, and $\mathrm{Ag}_{7} \mathrm{~S}_{\mathrm{m}}{ }^{-}$clusters, 3 for $\mathrm{Ag}_{3} \mathrm{~S}_{\mathrm{m}}{ }^{-}$, and 4 for $\mathrm{AgS}_{\mathrm{m}}{ }^{-}$and $\mathrm{Ag}_{5} \mathrm{~S}_{\mathrm{m}}{ }^{-}$. The largest sulfur binding energies are seen for $\mathrm{Ag}_{7} \mathrm{~S}_{2}{ }^{-}$which is particularly surprising since $\mathrm{Ag}_{7}{ }^{-}$has a closed electronic shell, so one would expect it to bind sulfur most weakly. The electron affinities of the clusters are plotted in Figure 5, and show that these clusters are all quite stable as anions. The electron affinity increases with the addition of sulfur as the $m=4 \mathrm{Ag}_{\mathrm{n}} \mathrm{S}_{\mathrm{m}}$ clusters all have the highest electron affinity for a given number of sulfur atoms, and the $m=0$ clusters all have the lowest electron affinity, except for $\mathrm{Ag}_{3}{ }^{-}$.

The HOMO-LUMO gaps of the neutral and anionic $\mathrm{Ag}_{n} \mathrm{~S}_{m}{ }^{0 /-}$ clusters are plotted in Figures 6(a) and 6(b) to examine the effect of the sulfur on the electronic shell structure. Figure 6(a) shows that the largest HOMO-LUMO gaps for the $\mathrm{Ag}_{\mathrm{n}}$ clusters are $\mathrm{Ag}_{2}$ and $\mathrm{Ag}_{6}$, as predicted by the nearly free electron model. The addition of sulfur decreases the HOMO-LUMO gap of nearly all of clusters, most notably in the $\mathrm{Ag}_{6} \mathrm{~S}_{\mathrm{m}}$ clusters with the $\mathrm{Ag}_{6}$ clusters having the largest gap and $\mathrm{Ag}_{6} \mathrm{~S}_{4}$ having the smallest. We note that the $\mathrm{Ag}_{6}$ cluster is expected to have a large gap with a planar structure,

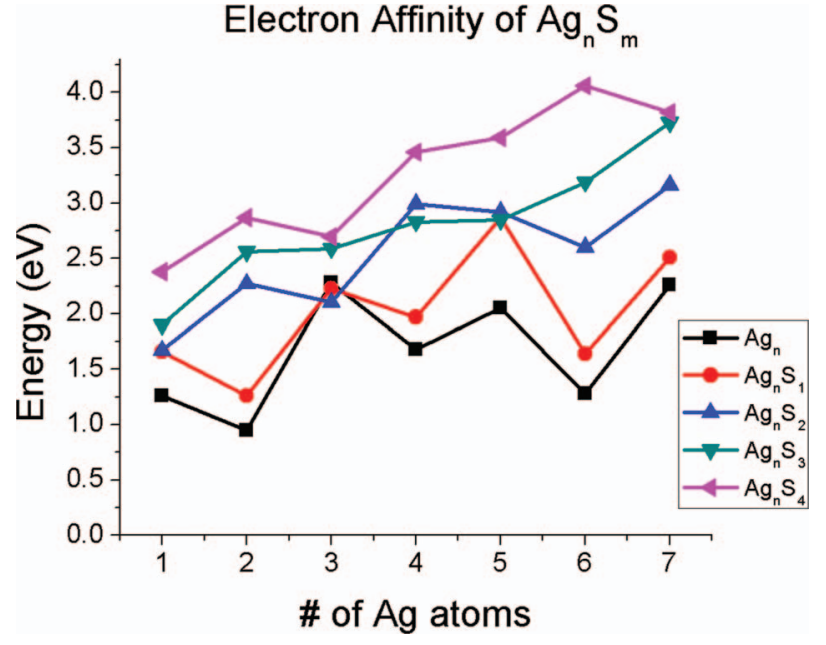

FIG. 5. Electron affinity (EA) of the $\operatorname{Ag}_{n} S_{m}$ clusters.

while both the $\mathrm{Ag}_{6}$ cluster in an octahedral geometry and the $\mathrm{Ag}_{6} \mathrm{~S}_{4}$ cluster which has a compact distorted octahedral structure have ground states with two unpaired electrons. If the sulfur was reducing the effective valence electron count of the cluster, the $\mathrm{Ag}_{6} \mathrm{~S}_{4}$ would have an effective valence electron count of 2, which would result in a closed electronic shell. The

(a)

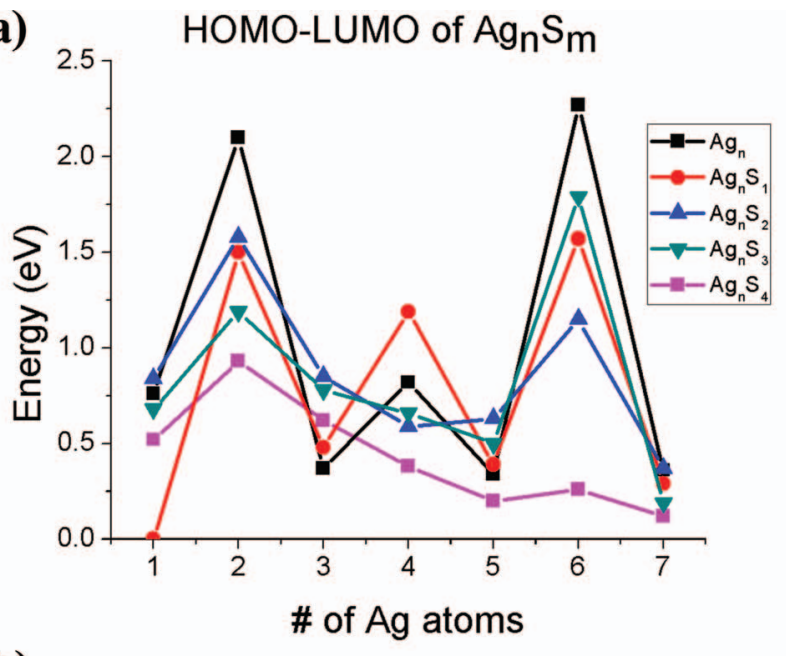

(b)

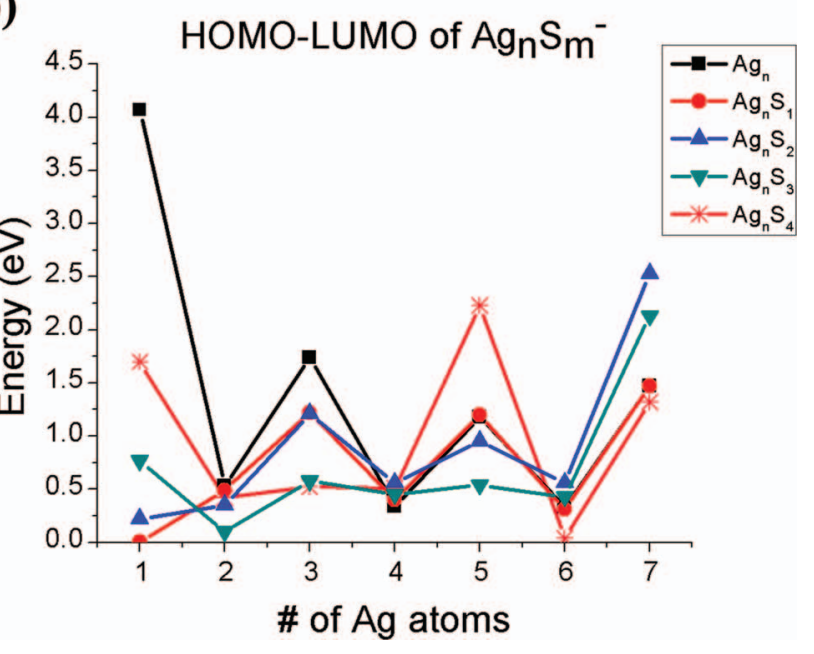

FIG. 6. Plot of the HOMO-LUMO gap energies of (a) netural $\mathrm{Ag}_{n} \mathrm{~S}_{m}$ and (b) anions. 


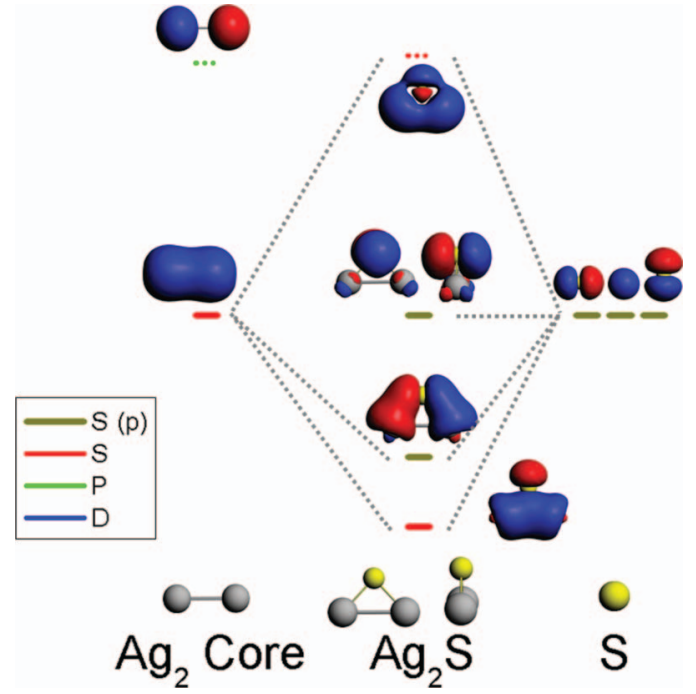

FIG. 7. One electron energy level schematic of the bonding between the $\mathrm{Ag}_{2}$ and $\mathrm{S}$ atom form the $\mathrm{Ag}_{2} \mathrm{~S}$ cluster.

fact that the octahedral $\mathrm{Ag}_{6} \mathrm{~S}_{4}$ cluster is maintaining the same spin multiplicity as the $\mathrm{Ag}_{6}$ octahedral core suggests that the sulfur bonding is not disrupting the electronic shell structure of the $\mathrm{Ag}_{6}$ core, although further analysis of the electronic structure is needed.

Figure 6(b) shows the HOMO-LUMO gaps of the $\mathrm{Ag}_{\mathrm{n}} \mathrm{S}_{\mathrm{m}}{ }^{-}$anions. Note that the unusually large gap of $\mathrm{Ag}^{-}$ distorts the scale as compared to Figure 6(a). An even odd oscillation is seen with the $\mathrm{Ag}_{5} \mathrm{~S}_{4}{ }^{-}$having an especially large HOMO-LUMO gap, and the $\mathrm{Ag}_{7} \mathrm{~S}_{\mathrm{m}}{ }^{-}$series being of particular interest. $\mathrm{Ag}_{7}{ }^{-}$is interesting because its HOMO-LUMO gap is $1.47 \mathrm{eV}$, which is expected based on it having a closed electronic shell in the spherical jellium model with 8 valence electrons. The bonding with sulfur results in the $\mathrm{Ag}_{7} \mathrm{~S}^{-}$, $\mathrm{Ag}_{7} \mathrm{~S}_{2}{ }^{-}$, and $\mathrm{Ag}_{7} \mathrm{~S}_{3}{ }^{-}$all having the same or larger HOMO-
LUMO gaps than $\mathrm{Ag}_{7}{ }^{-} . \mathrm{Ag}_{7} \mathrm{~S}_{4}{ }^{-}$has a smaller gap than $\mathrm{Ag}_{7}{ }^{-}$, but it is still a respectable $1.32 \mathrm{eV}$. If the bonding with sulfur was reducing the effective valence electron count, then the HOMO-LUMO gap would decrease with the addition of sulfur. The HOMO-LUMO gaps indicate that the effect of sulfur bonding causes the HOMO-LUMO gap of the $\mathrm{Ag}_{6} \mathrm{~S}_{\mathrm{m}}$ clusters to decrease while producing a compact metal core, while in the case of $\mathrm{Ag}_{7} \mathrm{~S}_{\mathrm{m}}{ }^{-}$, the HOMO-LUMO gap is maintained.

Before we proceed further, let us examine the nature of bonding between $\mathrm{Ag}$ and $\mathrm{S}$ in detail by considering the electronic structure of the $\mathrm{Ag}_{2} \mathrm{~S}$ cluster, the simplest silver-sulfur cluster. Figure 7 shows the molecular orbital picture of $\mathrm{Ag}_{2}$ and $\mathrm{S}$ combining to form $\mathrm{Ag}_{2} \mathrm{~S}$. The $\mathrm{Ag}_{2}$ has two valence electrons, and has a HOMO-LUMO gap of $2.10 \mathrm{eV}$. The addition of a single sulfur results in a structure in which the $S$ binds in a 2-coordinated site to both silver atoms, also seen in Fig. 7. The $\mathrm{Ag}-\mathrm{Ag}$ bond length expands from $2.60 \AA$ in $\mathrm{Ag}_{2}$ to $3.16 \AA$, and the HOMO-LUMO gap decreases to still a relatively large value of $1.50 \mathrm{eV}$. The sulfur $3 p$ orbitals introduce three new orbitals, the lowest energy of which is a bonding orbital perpendicular to the surface of the cluster. The next lowest orbital is a more weakly bonding orbital where the $3 p$ orbital of sulfur is parallel with the silver dimer, and the HOMO is a nonbonding orbital in which the $3 p$ orbital of sulfur is perpendicular to the silver dimer. The LUMO is an antibonding orbital where the $3 p$ orbital of sulfur is of opposite phase as the lowest energy valence orbital. The sulfur provides four valence electrons, and the $\mathrm{Ag}_{2}$ provides two valence electrons. The overall shell structure of $\mathrm{Ag}_{2}$ is still intact within $\mathrm{Ag}_{2} \mathrm{~S}$, and the two orbitals of weakly bonded or lone pair primarily located on the sulfur are filled, becoming the frontier orbitals.

To understand the effect of sulfur on the electronic structure of $\mathrm{Ag}_{6} \mathrm{~S}_{\mathrm{m}}$ and $\mathrm{Ag}_{7} \mathrm{~S}_{\mathrm{m}}{ }^{-}$, their density of states along with their projected density of states is displayed in Figure 8. We also employ the tool of Overlap Population Density of States (OPDOS) in which a positive OPDOS points to constructive

(a)

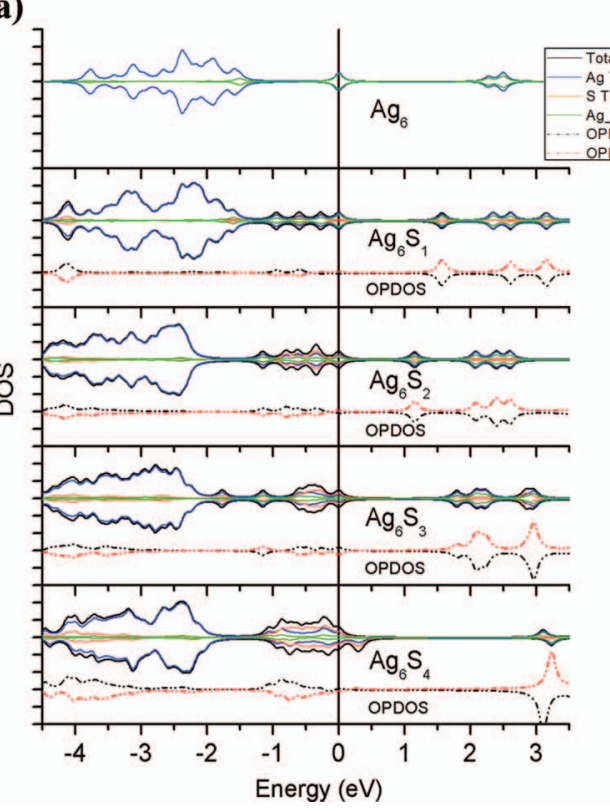

(b)

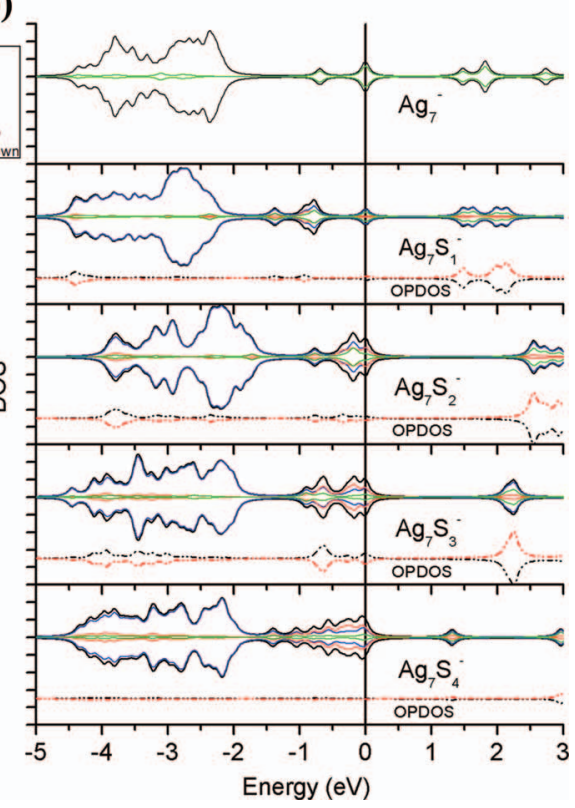

FIG. 8. Density of States, Projected Density of States, and OPDOS plots for $\mathrm{Ag}_{6} \mathrm{~S}_{m}$ (a) and $\mathrm{Ag}_{7} \mathrm{~S}_{m}{ }^{-}$(b), $m=0-4$. 
interference between the $\mathrm{Ag}$ and $\mathrm{S}$ orbitals indicating covalent bonding, and a negative OPDOS points to destructive interference between the $\mathrm{Ag}$ and $\mathrm{S}$ orbitals indicating an antibonding orbital. ${ }^{58,63}$ In our plots the black OPDOS is for the spin up channel, and the red in for the spin down, and the sign of the OPDOS has been inverted. In all plots, the $4 d$ silver bands are prominent from -4.5 to $-2.0 \mathrm{eV}$, while the green $\mathrm{Ag} 5 s$ projected DOS indicate the delocalized orbitals are found mostly in the range of -2 to $0 \mathrm{eV}$. The sulfur states are most dense in this range as well, near the HOMO level, with some arising below the $4 d$ band. Using the OPDOS plots we can verify that the sulfur density present below the $4 d$ bands is bonding in nature, while the negative OPDOS of the LUMOs in all cases shows that they are antibonding. This is consistent with the molecular orbital plot from Figure 7, with one set of deep bonding orbitals appearing with a number of weakly bonding and nonbonding orbitals appearing at or near the HOMO. The presence of large density of $5 s$ orbitals states also indicates that the delocalized orbitals of the metallic cluster are still occupied and are near the frontier orbitals. Another similarity between these densities of states and the simple picture in $\mathrm{Ag}_{2} \mathrm{~S}$ is that the LUMO of these clusters, except for $\mathrm{Ag}_{6} \mathrm{~S}_{4}$, are all antibonding Ag-S orbitals. The density of states reveals two energy regions that are predominantly due to $\mathrm{S}$, one deep in the energy spectrum, and a second near the HOMO, and that the LUMO of most of the $\mathrm{Ag}_{\mathrm{n}} \mathrm{S}_{\mathrm{m}}$ clusters are antibonding orbitals between the silver and sulfur.

We next examine the molecular orbital diagrams of $\mathrm{Ag}_{6} \mathrm{~S}$ to examine the electronic structure. The top panel of Figure 9 shows the planar structure of $\mathrm{Ag}_{6}$ and its large HOMO-LUMO gap of $2.27 \mathrm{eV}$. This gap size is explained by the structure of the cluster itself, which contains an electronic structure of delocalized $\mathrm{Ag} 5 s$ states $\left|1 \mathrm{~S}^{2}\right| 1 \mathrm{P}^{4} \| 1 \mathrm{P}^{2} \mid$, where capital letters represent the jellium-like delocalized orbital. This delocalized orbital representation also describes $\mathrm{Ag}_{6} \mathrm{~S}$, where adding $\mathrm{S}$ to form $\mathrm{Ag}_{6} \mathrm{~S}$ result in two $1 \mathrm{P}$ orbitals, shown in green in Fig. 9, are still occupied. The sulfur provides one deep bonding orbital, and two lone-pair orbitals, but the electronic shell structure of the silver is still discernible.

The molecular orbital diagrams of $\mathrm{Ag}_{6} \mathrm{~S}_{2}, \mathrm{Ag}_{6} \mathrm{~S}_{3}$, and $\mathrm{Ag}_{6} \mathrm{~S}_{4}$ are shown in the middle and bottom panels of Figure 9. We can see that both $\mathrm{Ag}_{6} \mathrm{~S}_{2}$ and $\mathrm{Ag}_{6} \mathrm{~S}_{3}$ have three molecular orbitals that can be assigned as $1 \mathrm{P}$, resulting in the filling of the $1 \mathrm{P}^{6}$ shell. The fragment containing $\mathrm{Ag}_{6}$ in the geometry of $\mathrm{Ag}_{6} \mathrm{~S}_{2}$ has a near degeneracy at the HOMO, with a HOMOLUMO gap of only $0.1 \mathrm{eV}$, and that the addition of $\mathrm{S}$ results in 3 lone pair orbitals for a total of 6 orbitals above the $4 d$ band. $\mathrm{Ag}_{6} \mathrm{~S}_{3}$ has a disulfide bond resulting in only 4 lone pair orbitals above the $4 d$ band, as the disulfide bonding orbital is lower in energy.

The electronic structure of $\mathrm{Ag}_{6} \mathrm{~S}_{4}$ has two unpaired electrons which result from having 11 orbitals above the $4 d$ band, 3 of which correspond to the filling of the $1 \mathrm{P}^{6}$ shell, and 8 corresponding to the lone pair on sulfur. There are only 20 electrons available to fill these orbitals, and because the sulfur prefers to bind to a 3-coordinated site the cluster is unable to Jahn-Teller distort to quench its magnetic moment. The $\mathrm{Ag}_{6}$ fragment in the geometry of $\mathrm{Ag}_{6} \mathrm{~S}_{4}$ also has two unpaired electrons. This demonstrates that the metallic shell is

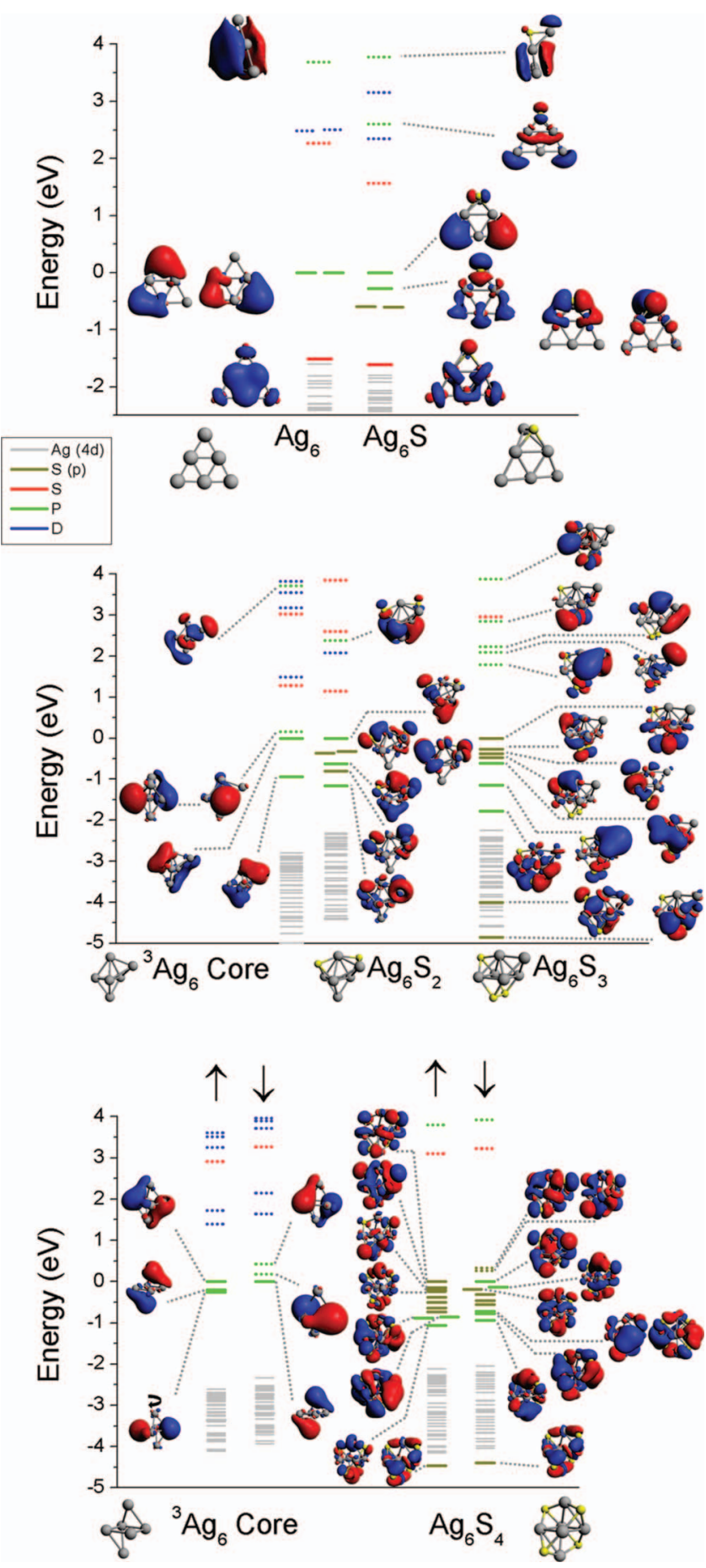

FIG. 9. The one electron energy levels and associated molecular orbital isosurfaces of $\mathrm{Ag}_{6} \& \mathrm{Ag}_{6} \mathrm{~S} ;{ }^{3} \mathrm{Ag}_{6}$ Core, $\mathrm{Ag}_{6} \mathrm{~S}_{2} \& \mathrm{Ag}_{6} \mathrm{~S}_{3} ;{ }^{3} \mathrm{Ag}_{6}$ Core \& $\mathrm{Ag}_{6} \mathrm{~S}_{4}$, arrows for spin-up and spin-down, respectively.

still discernible is $\mathrm{Ag}_{6} \mathrm{~S}_{4}$ even though the sulfur has bonded with the cluster.

Next we examine the $\mathrm{Ag}_{7} \mathrm{~S}_{m}{ }^{-}$clusters, where their pure cluster analogues already have a closed electronic shell. The top panel of Figure 10 shows the one electron levels of the $\mathrm{Ag}_{7}{ }^{-}$core belonging to the $\mathrm{Ag}_{7} \mathrm{~S}^{-}$cluster. Surprisingly, the ground state structure results in an open metallic core in which the electronic shell structure is $1 \mathrm{P}^{4}$, with the $1 \mathrm{P}_{\mathrm{z}}$ orbital antibonding in character with sulfur serving as the LUMO. 

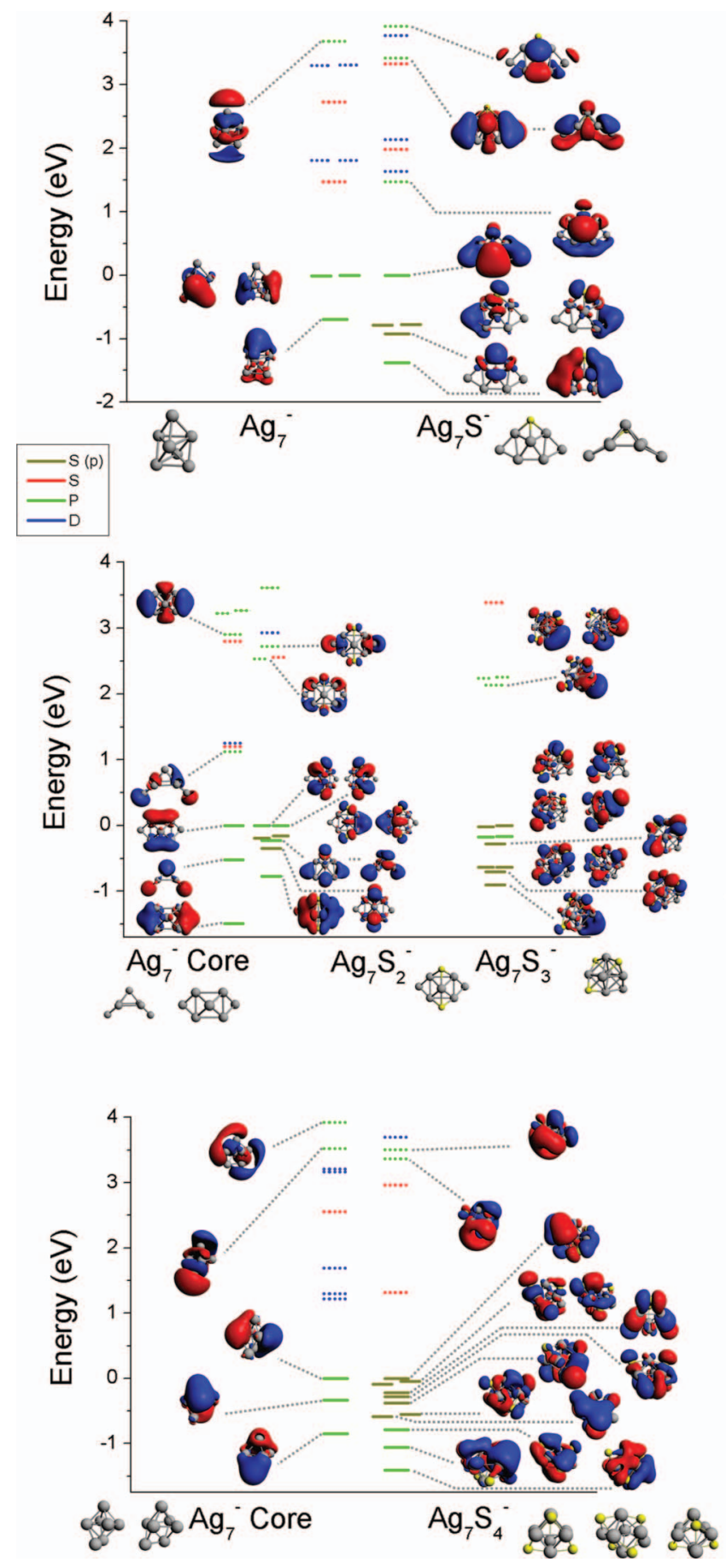

FIG. 10. The one electron energy levels and associated molecular orbital isosurfaces of $\mathrm{Ag}_{7}{ }^{-} \& \mathrm{Ag}_{7} \mathrm{~S}^{-} ; \mathrm{Ag}_{7}{ }^{-}$Core, $\mathrm{Ag}_{7} \mathrm{~S}_{2}{ }^{-} \& \mathrm{Ag}_{7} \mathrm{~S}_{3}{ }^{-} ; \mathrm{Ag}_{7}{ }^{-}$Core $\& \mathrm{Ag}_{7} \mathrm{~S}_{4}^{-}$.

The cluster still has 5 orbitals above the $4 d$ band, so this may be due to one of the $1 \mathrm{P}$ orbitals hybridizing with the lone pair. For the $\mathrm{Ag}_{7} \mathrm{~S}_{2}{ }^{-}$cluster and $\mathrm{Ag}_{7} \mathrm{~S}_{3}{ }^{-}$cluster, as shown in Figure 10 (middle panel), the $1 \mathrm{P}^{6}$ shell is full in both the $\mathrm{Ag}_{7}{ }^{-}$ cluster fragment and the $\mathrm{Ag}_{7} \mathrm{~S}_{2}{ }^{-}$and $\mathrm{Ag}_{7} \mathrm{~S}_{3}{ }^{-}$clusters. This shows that if the metallic core has a closed electronic shell, then the addition of sulfur maintains that closed shell character. The filled $\left|1 \mathrm{P}^{6}\right|$ orbital is also found in $\mathrm{Ag}_{7} \mathrm{~S}_{4}{ }^{-}$, with the electronic structure of the cluster above the $4 d$ band consisting of 8 lone pair orbitals and 3 orbitals filling the $1 \mathrm{P}^{6}$ shell.

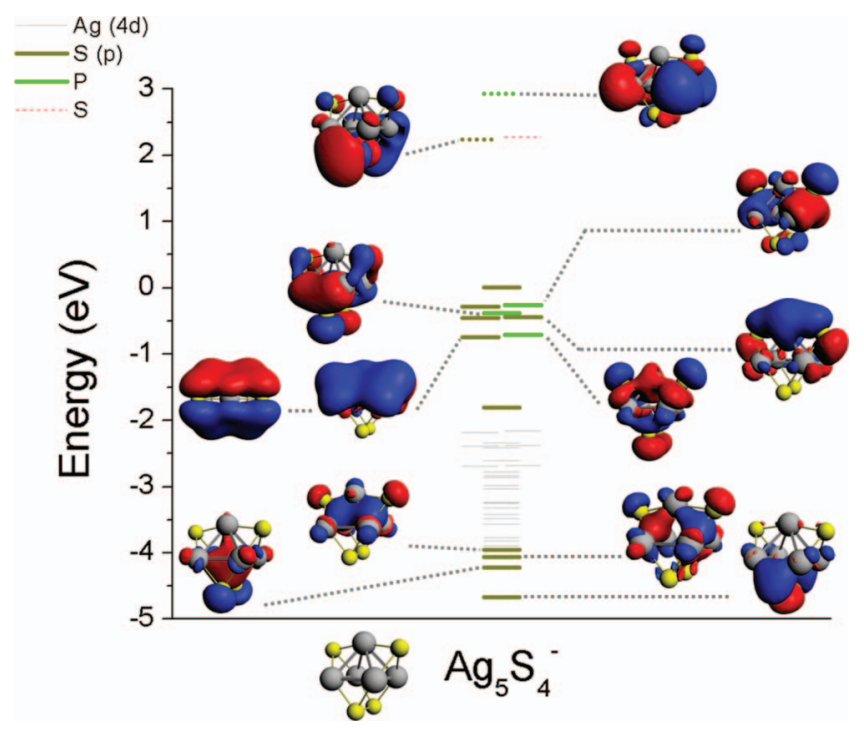

FIG. 11. The one electron energy levels and associated molecular orbital isosurfaces of $\mathrm{Ag}_{5} \mathrm{~S}_{4}{ }^{-}$.

This demonstrates that the bonding between sulfur and a silver cluster results in a deep bonding orbital per sulfur atom, and two weakly bonding/nonbonding orbitals per sulfur atom. Furthermore, the electronic shell structure of the Ag cluster is still discernible after the addition of the sulfur.

Lastly we examine the electronic structure of $\mathrm{Ag}_{5} \mathrm{~S}_{4}{ }^{-}$because of its large $2.24 \mathrm{eV}$ HOMO-LUMO gap, to understand the origin of its stability. The metallic core has a pyramidal structure, with two sulfurs decorating the faces of the pyramid, and two more forming a disulfide bond on the square face of the metallic core. The electronic structure reveals three deep bonding orbitals between the silver core and sulfur, a disulfide bond orbital, a filled $1 \mathrm{P}^{6}$ shell, and 6 lone pair orbitals. Figure 11 shows that the formation of the disulfide bond is due to two $3 p$ sulfur orbitals perpendicular to the metal core, which reduces the number of lone pair orbitals. This offers another mechanism which affects the electronic structure. In some ways, this is more similar to the bonding of a sulfur based ligand, which will have one fewer lone pair orbitals per ligand than the atomic sulfur. The combination of a closed $1 \mathrm{P}^{6}$ shell, and a disulfide bond results in the $\mathrm{Ag}_{5} \mathrm{~S}_{4}{ }^{-}$ having a much larger HOMO-LUMO gap than any other of the $\mathrm{Ag}_{5} \mathrm{~S}_{\mathrm{m}}{ }^{-}$clusters.

\section{CONCLUSION}

In summary, the geometric and electronic structures of neutral and anionic $\mathrm{Ag}_{n} \mathrm{~S}_{m}$ clusters have been investigated to understand the bonding and effect on the electronic shell structure of the silver core. It has been shown that the electronic shell structure of silver is maintained through subsequent additions of sulfur. This is demonstrated by the triplet multiplicity of the $\mathrm{Ag}_{6} \mathrm{~S}_{4}$ cluster, in which the preferred 3coordinate bonding site of sulfur results in the metallic core taking an octahedral structure. Because the bonding prevents a Jahn-Teller distortion from occurring, the cluster has the same triplet multiplicity of the $\mathrm{Ag}_{6}$ cluster in an octahedral 
structure. Secondly, the closed shell of $\mathrm{Ag}_{7}{ }^{-}$is retained after the addition of sulfur. Furthermore, one electron levels of the $\mathrm{Ag}_{\mathrm{n}} \mathrm{S}_{\mathrm{m}}$ clusters have occupied orbitals that correspond to the filling of the $1 \mathrm{P}^{6}$ shells. A simple molecular orbital picture for the bonding of sulfur to the metallic core is found in which one bonding orbital and two lone-pair orbitals are formed for each sulfur added. The exception to this rule is the case of the disulfide bond, which results in the reduction of one in the number of lone pair orbitals. These results verify that electron counting rules with the addition of sulfur are still valid and indicate the metallic shell structure of silver clusters bound by sulfur is surprisingly robust.

\section{ACKNOWLEDGMENTS}

We gratefully acknowledge support from the Air Force Office of Scientific Research through Grant No. FA9550-12$1-0481$.

${ }^{1}$ M. Faraday, Philos. Trans. R. Soc. London 147, 145 (1857).

${ }^{2}$ S. Mandal, A. C. Reber, M. Qian, P. S. Weiss, S. N. Khanna, and A. Sen, "Controlling the band gap energy of cluster-assembled materials," Acc. Chem. Res. (published online).

${ }^{3}$ C. E. Briant, B. R. C. Theobald, J. W. White, L. K. Bell, D. M. P. Mingos, and A. J. Welch, J. Chem. Soc. Chem. Commun. 1981, 201.

${ }^{4}$ P. D. Jadzinsky, G. Calero, C. J. Ackerson, D. A. Bushnell, and R. D. Kornberg, Science 318, 430 (2007).

${ }^{5}$ Y. Shichibu, Y. Negishi, T. Watanabe, N. K. Chaki, H. Kawaguchi, and T. Tsukuda, J. Phys. Chem. C 111, 7845 (2007).

${ }^{6}$ M. Zhu, C. M. Aikens, F. J. Hollander, G. C. Schatz, and R. Jin, J. Am. Chem. Soc. 130, 5883 (2008).

${ }^{7}$ M. B. Abreu, C. Powell, A. C. Reber, and S. N. Khanna, J. Am. Chem. Soc. 134, 20507 (2012).

${ }^{8}$ H. Häkkinen, Nat. Chem. 4, 443 (2012).

${ }^{9}$ M. W. Heaven, A. Dass, P. S. White, K. M. Holt, and R. W. Murray, J. Am. Chem. Soc. 130, 3754 (2008).

${ }^{10}$ D. E. Bergeron, O. Coskuner, J. W. Hudgens, and C. A. Gonzalez, J. Phys. Chem. C 112, 12808 (2008)

${ }^{11}$ P. R. Nimmala and A. Dass, J. Am. Chem. Soc. 133, 9175 (2011).

${ }^{12}$ H. Xiang, S.-H. Wei, and X. Gong, J. Am. Chem. Soc. 132, 7355 (2010).

${ }^{13}$ A. Dass, J. Am. Chem. Soc. 131, 11666 (2009).

${ }^{14}$ A. Dass, J. Am. Chem. Soc. 133, 19259 (2011).

${ }^{15}$ Z. Wu, E. Lanni, W. Chen, M. E. Bier, D. Ly, and R. Jin, J. Am. Chem. Soc. 131, 16672 (2009)

${ }^{16} \mathrm{G}$. Shafai, S. Hong, M. Bertino, and T. S. Rahman, J. Phys. Chem. C 113, 12072 (2009).

${ }^{17}$ K. M. Harkness, Y. Tang, A. Dass, J. Pan, N. Kothalawala, V. J. Reddy, D. E. Cliffel, B. Demeler, F. Stellacci, O. M. Bakr, and J. A. McLean, Nanoscale 4, 4269 (2012).

${ }^{18}$ D. Jiang, S. H. Overbury, and S. Dai, J. Am. Chem. Soc. 135, 8786 (2013).

${ }^{19}$ H. Yang, Y. Wang, H. Huang, L. Gell, L. Lehtovaara, S. Malola, H. Häkkinen, and N. Zheng, Nat. Commun. 4, 2422 (2013).

${ }^{20}$ H. Yang, J. Lee, B. Wu, Y. Wang, M. Zhou, A. Xia, and L. Zheng, Chem. Commun. 49, 300 (2013)

${ }^{21}$ M. D. Malinsky, K. L. Kelly, G. C. Schatz, and R. P. Van Duyne, J. Am. Chem. Soc. 123, 1471 (2001)

${ }^{22}$ H. Häkkinen, M. Walter, and H. Grönbeck, J. Phys. Chem. B 110, 9927 (2006)

${ }^{23}$ Y. Yanagimoto, Y. Negishi, H. Fujihara, and T. Tsukuda, J. Phys. Chem. B 110, 11611 (2006)

${ }^{24}$ U. Landman, B. Yoon, C. Zhang, U. Heiz, and M. Arenz, Top. Catal. 44, 145 (2007).

${ }^{25}$ M. Walter, J. Akola, O. Lopez-Acevedo, P. D. Jadzinsky, G. Calero, C. J. Ackerson, R. L. Whetten, H. Grönbeck, and H. Häkkinen, Proc. Natl. Acad. Sci. U.S.A. 105, 9157 (2008).
${ }^{26}$ K. Baishya, J. C. Idrobo, S. Öğüt, M. Yang, K. Jackson, and J. Jellinek, Phys. Rev. B 78, 075439 (2008).

${ }^{27}$ C. Noguez and I. L. Garzón, Chem. Soc. Rev. 38, 757 (2009).

${ }^{28}$ D. M. Alloway, A. L. Graham, X. Yang, A. Mudalige, R. Colorado, V. H. Wysocki, J. E. Pemberton, T. Randall Lee, R. J. Wysocki, and N. R. Armstrong, J. Phys. Chem. C 113, 20328 (2009).

${ }^{29}$ I. Díez, M. Pusa, S. Kulmala, H. Jiang, A. Walther, A. S. Goldmann, A. H. E. Müller, O. Ikkala, and R. H. A. Ras, Angew. Chem., Int. Ed. 48, 2122 (2009).

${ }^{30}$ O. M. Bakr, V. Amendola, C. M. Aikens, W. Wenseleers, R. Li, L. Dal Negro, G. C. Schatz, and F. Stellacci, Angew. Chem. 121, 6035 (2009).

${ }^{31}$ O. Lopez-Acevedo, K. A. Kacprzak, J. Akola, and H. Häkkinen, Nat. Chem. 2, 329 (2010).

${ }^{32}$ J. Akola, K. A. Kacprzak, O. Lopez-Acevedo, M. Walter, H. Grönbeck, and H. Häkkinen, J. Phys. Chem. C 114, 15986 (2010).

${ }^{33}$ C. M. Aikens, J. Phys. Chem. Lett. 2, 99 (2011).

${ }^{34}$ S. Malola and H. Häkkinen, J. Phys. Chem. Lett. 2, 2316 (2011).

${ }^{35}$ P. A. Clayborne, O. Lopez-Acevedo, R. L. Whetten, H. Gronbeck, and H. Hakkinen, J. Chem. Phys. 135, 094701 (2011).

${ }^{36}$ A. Dass, Nanoscale 4, 2260 (2012).

${ }^{37}$ E. B. Guidez, V. Mäkinen, H. Häkkinen, and C. M. Aikens, J. Phys. Chem. C 116, 20617 (2012).

${ }^{38}$ S. R. Biltek, S. Mandal, A. Sen, A. C. Reber, A. F. Pedicini, and S. N. Khanna, J. Am. Chem. Soc. 135, 26 (2013).

${ }^{39}$ S. N. Khanna and P. Jena, Phys. Rev. B 51, 13705 (1995).

${ }^{40}$ W. D. Knight, K. Clemenger, W. A. de Heer, W. A. Saunders, M. Y. Chou, and M. L. Cohen, Phys. Rev. Lett. 52, 2141 (1984).

${ }^{41}$ M. Brack, Rev. Mod. Phys. 65, 677 (1993).

${ }^{42}$ A. C. Reber, S. N. Khanna, P. J. Roach, W. H. Woodward, and A. W. Castleman, J. Am. Chem. Soc. 129, 16098 (2007).

${ }^{43}$ Z. Luo, G. U. Gamboa, J. C. Smith, A. C. Reber, J. U. Reveles, S. N. Khanna, and A. W. Castleman, J. Am. Chem. Soc. 134, 18973 (2012).

${ }^{44}$ K. Clemenger, Phys. Rev. B 32, 1359 (1985).

${ }^{45}$ P. J. Roach, W. H. Woodward, A. C. Reber, S. N. Khanna, and A. W. Castleman, Phys. Rev. B 81, 195404 (2010).

${ }^{46}$ Z. Luo, C. J. Grover, A. C. Reber, S. N. Khanna, and A. W. Castleman, J. Am. Chem. Soc. 135, 4307 (2013).

${ }^{47}$ M. Shen, S. M. Russell, D.-J. Liu, and P. A. Thiel, J. Chem. Phys. 135, 154701 (2011).

${ }^{48}$ A. C. Reber, G. U. Gamboa, and S. N. Khanna, J. Phys. Conf. Ser. 438, 012002 (2013).

${ }^{49}$ M. Yang, K. A. Jackson, and J. Jellinek, J. Chem. Phys. 125, 144308 (2006).

${ }^{50}$ R. Fournier, J. Chem. Phys. 115, 2165 (2001).

${ }^{51}$ E. M. Fernández, J. M. Soler, I. L. Garzón, and L. C. Balbás, Phys. Rev. B 70, 165403 (2004).

${ }^{52}$ J. Hagen, L. D. Socaciu, J. Le Roux, D. Popolan, T. M. Bernhardt, L. Wöste, R. Mitrić, H. Noack, and V. Bonačić-Koutecký, J. Am. Chem. Soc. 126, 3442 (2004).

${ }^{53}$ Z. Wu, D. Jiang, E. Lanni, M. E. Bier, and R. Jin, J. Phys. Chem. Lett. 1, $1423(2010)$.

${ }^{54}$ P. Liu, C. Han, Z. Gao, F. Kong, and Q. Zhu, J. Phys. Chem. B 103, 3337 (1999).

${ }^{55}$ A. A. Bagatur'yants, A. A. Safonov, H. Stoll, and H.-J. Werner, J. Chem. Phys. 109, 3096 (1998).

${ }^{56} \mathrm{H}$. Woldeghebriel and A. Kshirsagar, J. Chem. Phys. 127, 224708 (2007)

${ }^{57}$ J. P. Perdew, K. Burke, and M. Ernzerhof, Phys. Rev. Lett. 77, 3865 (1996).

${ }^{58}$ G. te Velde, F. M. Bickelhaupt, E. J. Baerends, C. Fonseca Guerra, S. J. A. van Gisbergen, J. G. Snijders, and T. Ziegler, J. Comput. Chem. 22, 931 (2001).

${ }^{59}$ E. van Lenthe, A. Ehlers, and E.-J. Baerends, J. Chem. Phys. 110, 8943 (1999).

${ }^{60}$ W. H. Woodward, A. C. Reber, J. C. Smith, S. N. Khanna, and A. W. Castleman, J. Phys. Chem. C 117, 7445 (2013).

${ }^{61}$ B. Simard, P. A. Hackett, A. M. James, and P. R. R. Langridge-Smith, Chem. Phys. Lett. 186, 415 (1991).

${ }^{62}$ Q. Ran, R. W. Schmude, K. A. Gingerich, D. W. Wilhite, and J. E. Kingcade, J. Phys. Chem. 97, 8535 (1993).

${ }^{63}$ T. Hughbanks and R. Hoffman, J. Am. Chem. Soc. 105, 3528-3527 (1983). 